\title{
In Search of the Antecedents of Adolescent Authoritarianism: The Relative Contribution of Parental Goal Promotion and Parenting Style Dimensions
}

\author{
BART DURIEZ* ${ }^{*}$ BART SOENENS and MAARTEN VANSTEENKISTE \\ KU Leuven, Leuven, Belgium
}

\begin{abstract}
Although research drew attention to the importance of both parental goal promotion and parental rearing style in explaining adolescent authoritarian submission (Right-Wing Authoritarianism or RWA) and authoritarian dominance (Social Dominance Orientation or SDO), research failed to examine their combined effects. This study examines the relative contribution of parenting goals (i.e. extrinsic vs. intrinsic and conservation goals) and styles (i.e. need support and regulation) and their interactions in the prediction of adolescent RWA and SDO. Cross-sectional analyses show that, whereas parenting goals and styles and their interactions predict RWA, SDO is predicted by parental goals only. However, in a second, longitudinal study, changes in RWA and SDO were predicted by parenting goals only. Copyright (C) 2007 John Wiley \& Sons, Ltd.
\end{abstract}

Key words: attitudes; personality types; social and personal relationships; development of personality; parenting

\section{INTRODUCTION}

Two research lines dominate the quest for the antecedents of prejudice. The first views prejudice as resulting from group processes (e.g. Tajfel \& Turner, 1979). The second regards it as a result of dispositional factors making people more or less prone to adopt prejudice. Within the latter tradition, two individual difference dimensions have been identified as important and relatively independent prejudice predictors. The first, Right-Wing Authoritarianism (RWA), is defined as the covariation of an adherence to conventional norms and values, an uncritical subjection to authority, and feelings of aggression towards norm violators (Altemeyer, 1981). The second, the Social Dominance Orientation (SDO), delineates the extent to which one desires the ingroup to dominate

*Correspondence to: Bart Duriez, Department of Psychology, KU Leuven, Tiensestraat 102, Leuven 3000, Belgium. E-mail: bart.duriez@psy.kuleuven.be 
outgroups (Pratto, Sidanius, Stallworth, \& Malle, 1994). According to Altemeyer (1998), RWA and SDO constitute two facets of the original Authoritarian Personality as originally described by Adorno, Frenkel-Brunswik, Levinson, and Sanford (1950), with RWA referring to authoritarian submission and SDO referring to authoritarian dominance.

Although plenty of research substantiates the importance of RWA and SDO, only few studies examined how these dispositions develop within the individual. In this respect, the importance of particular phases in life constitutes an important issue. In general, three explanatory models are found with regard to political socialisation (Sears, 1990): Formative phase models that assume that different attitudinal dispositions develop at different periods in life; impressionable years models that assume that adolescence represents the critical age period for the development of any attitudinal disposition and lifelong openness models that presuppose lifelong development. These different socialisation models need not necessarily be seen as mutually exclusive: The assumption of lifelong development does not contradict the idea that particular phases in life are characterised by a heightened susceptibility to change and development (Vollebergh, Iedema, \& Raaijmakers, 2001). Partly because of this, the formative phase model has been the most prominent in the theorising on authoritarianism.

Adorno et al. (1950) assumed that authoritarianism is formed during early childhood. A childhood characterised by harsh punishment and little parental warmth would produce a personality that is characterised by a glorification of parental authority and by displacement of rage occasioned by the parents onto a variety of despised outgroups. Although there is some empirical evidence for this position (Milburn, Conrad, Sala, \& Carberry, 1995), support has not been strong (Altemeyer, 1981, 1998; Duckitt, 2001; Sears, 1990). Contrary to Adorno et al. (1950), Altemeyer (1998) assumes that authoritarian attitudes, which are acquired from other people (through teaching or modelling) and from our own experiences, are open to lifelong development. However, at the same time, he considers adolescence to be the crucial formative phase, and attitudes that are acquired in this period would be fairly resistant to change. In line with Altemeyer, researchers have recently argued that RWA and SDO do not represent core personality traits, but should be conceptualised as sets of relatively malleable cognitive beliefs (Duckitt, 2001; Duriez, Van Hiel, \& Kossowska, 2005; Van Hiel, Pandelaere, \& Duriez, 2004) or surface personality traits (Asendorpf \& van Aken, 2003) that become relativly stable in adolescence only (e.g. Duckitt, Wagner, du Plessis, \& Birum, 2002; Vollebergh \& Raaijmakers, 1991). In line with these recent conceptions of RWA and SDO, in the present study, we will focus on adolescence.

The theory of Altemeyer (1998) does not only differ from Adorno et al. (1950) by considering another phase in life as crucial for the formation of authoritarianism (i.e. adolescence vs. early childhood), it also differs from the theory of Adorno et al. (1950) in the nature of this influence. According to Altemeyer (1998), parents need not be harsh and unresponsive to produce authoritarian offspring, and need not use punishments to ensure their children conform to their expectations. Merely teaching children to adhere to norms and to obey authority (for RWA) or teaching them that one can only get ahead in life at the expense of others (for SDO) might suffice. Altemeyer's (1988) focus on the type of goals parents promote fits with Darling and Steinberg's (1993) argument that, in order to understand the parental influence, one should not only consider parents' rearing style (i.e. how parents socialise their children) but also the type of goals they promote (i.e. what parents socialise in their children). Whereas parenting style dimensions provide an indication of the emotional climate within the family (i.e. parental need support) and of 
whether or not parents attempt to provide guidance and structure to the child's goals and behaviours (i.e. parental regulation), parental goal promotion efforts determine which goals and behaviours are encouraged (Vansteenkiste, Duriez, Soenens, \& De Witte, 2006).

\section{Parental goal promotion}

Self-Determination Theory (Deci \& Ryan, 2000) categorises the goals people pursue as either intrinsic or extrinsic in nature (Kasser \& Ryan, 1996; Vansteenkiste, Lens, \& Deci, 2006). Intrinsic goals (i.e. community contribution, self-development and affiliation) are considered inherently satisfying to pursue and are said to be consistent with the satisfaction of the basic psychological needs for autonomy, competence and relatedness. In contrast, when people pursue extrinsic goals (i.e. wealth, social recognition and physical attractiveness), they hang their endeavours upon the attainment of external signs of worth and success and such an extrinsic goal pursuit is said to be unrelated or even negatively related to basic need satisfaction (Kasser, 2002).

Research has primarily examined the correlates of personal extrinsic versus intrinsic (E/I) goal pursuits. A stronger focus on extrinsic rather than intrinsic goals was found to negatively predict well-being (Kasser, 2002), to positively predict RWA (Vansteenkiste, Duriez et al., 2006) and to foster an increase in SDO over time (Duriez, Vansteenkiste, Soenens, \& De Witte, in press). Because people with an extrinsic rather than an intrinsic goal focus are more concerned about the impression they make, they are more likely to engage in stressful interpersonal comparisons (e.g. Vansteenkiste, Simons, Lens, Soenens et al., 2004) and more likely to experience feelings of insecurity, which would arouse RWA (Duckitt, 2001). In addition, an extrinsic rather than an intrinsic goal focus would give rise to a view of the world as a competitive jungle, which arouses SDO (Duckitt, 2001).

Recently, it has been argued that E/I goals cannot only be pursued to different degrees by individuals, but can also be promoted to a different extent by socialising agents such as teachers and parents (Vansteenkiste, Lens et al., 2006). Furthermore, it was shown that differences in E/I goal promotion have a negative effect on individual functioning (e.g. Vansteenkiste, Simons, Lens, Sheldon, \& Deci, 2004), and that parental E/I goal promotion predicts adolescent RWA and SDO (Vansteenkiste, Duriez et al., 2006). The effect of parental goal promotion on RWA and SDO could be accounted for by adolescents' adoption and individual pursuit of E/I goals.

A second type of goals which is relevant to the study of RWA and SDO pertains to conformity. Duckitt (2001) has shown that, whereas social conformity is unrelated to SDO, it is highly important for the formation of RWA. Conformity was not present in the original distinction between intrinsic and extrinsic goals (Kasser \& Ryan, 1996), but has recently been found to cluster together with the original extrinsic goals in a circumplex model that generally held across 15 different cultures (Grouzet et al., 2006). However, the location of conformity in the extrinsic goal pole seems inconsistent with Schwartz' (1992), who found the value domain to consist of the orthogonal dimensions Self-Enhancement versus Self-Transcendence, encompassing power values that relate to an extrinsic goal content, and Conservation versus Openness to Change, encompassing conformity values. Building on Schwartz' value conceptualisation, Duriez and colleagues (Duriez \& Van Hiel, 2002; Duriez et al., 2005) have shown that the Conservation versus Openness to Change values dimension relates to RWA but not to SDO. As it remains relatively unclear whether conformity should be considered an extrinsic goal, as suggested by Grouzet et al. (2006), or 
is essentially unrelated to the distinction between intrinsic and extrinsic goals, as suggested by Schwartz (1992), we will examine the factor structure of our parental goal questionnaire. If conformity turns out to represent a separate goal, we predict it to primarily relate to RWA, as past research has suggested (e.g. Duckitt, 2001; Duriez \& Van Hiel, 2002).

\section{Parenting style dimensions}

It is widely acknowledged in the socialisation literature that there are two fundamental components underlying the parenting style construct, that is, a component pertaining to the affective quality of the parent-child relationship (parental support) and a component relating to parents regulatory and structuring capacities (parental regulation) (Barber, 1997; Maccoby \& Martin, 1983).

In the socialisation literature, parental support is often viewed as a multidimensional construct, as it refers to the degree to which adolescents experience a warm, responsive and personal relation with their parents as well as to the extent to which parents provide autonomy-support and refrain from intrusive and manipulative parenting techniques such as guilt-induction and love withdrawal. From a self-determination perspective (Grolnick, 2003), responsive parenting is likely to meet adolescents' basic need for relatedness (Baumeister \& Leary, 1995), whereas an autonomy-supportive family climate is likely to satisfy adolescents' need for autonomy (Deci, 1975). Responsiveness and autonomysupport versus controlling parenting have sometimes been combined in previous work and this composite score was referred to as need supportive (Niemiec et al., 2006) or nurturant (Kasser, Ryan, Zax, \& Sameroff, 1995) parenting. Studies have shown that need-supportive parenting is positively related to various adjustment indicators, such as psychological well-being, social competence and self-esteem (Gray \& Steinberg, 1999; Maccoby \& Martin, 1983; Niemiec et al., 2006). Parental regulation refers to active parental strategies involving the communication of clear expectations and limits for appropriate behaviour and efforts to monitor the child's behaviour (Barber, 2002). Adequate parental regulation should teach children to self-regulate and become less susceptible to negative peer influences and, hence, prevent them from engaging in antisocial behaviour (Barber, 1996, 1997, 2002).

Although parenting styles were prominent in the theory of Adorno et al. (1950), interest in them declined when research yielded little support for the claim that childhood socialisation was the key to understand the Authoritarian Personality (Altemeyer, 1981, 1998; Duckitt, 2001; Sears, 1990). Although adolescent representations of parenting styles are related to crucial dimensions of adolescents' psychosocial functioning and although Altemeyer (1998) pays explicit attention to parental influence, the shift to adolescence as the formative phase for authoritarianism was not accompanied by a renewed interest in parenting style effects. In spite of this, specific predictions can be made. According to Duckitt (2001), lack of parental need support should predict SDO because it would make people hard, tough, ruthless, unfeeling and cynical, and these are all characteristics that apply to social dominators. In contrast, lack of parental need support would hinder the development of RWA because people who experience little support from their primary attachment figures are less likely to build attachments to other people and the society as a whole. Hence, people who received little parental support would be less likely to value obedience, respect for authority and the like. Additionally, high levels of parental 
regulation should predict RWA because parents high on regulation stress the importance of parental authority and obedience. In line with this, Duckitt (2001) found strict versus permissive parenting, which bears some similarity with parental regulation, to positively predict RWA. In sum, based on previous research, we expect a negative effect of parental need support on SDO, a positive effect of parental need support on RWA and a positive effect of parental regulation on RWA.

\section{Goal-style interactions}

Although research to date has examined parenting styles and goals as independent sources of influence on adolescent authoritarianism, research on the transmission of values and goals suggests that parents will only be successful in their goal promotion if their children perceive these goals and adopt them. Parenting styles would serve as important determinants of the extent to which adolescents adopt the goals that parents hold or promote (Grusec, Goodnow, \& Kuczynski, 2000; Knafo \& Schwartz, 2003). Applying this reasoning to the present context, one may expect that parenting styles may impact on the degree to which parental goal promotion carries over into adolescents' development of RWA and SDO. Therefore, it was deemed important to assess the combined and interactive effects of parenting goals and styles in the prediction of RWA and SDO. Specifically, parental need support may be particularly important in this regard, as this parenting dimension is thought to enhance the desire to spend time with the parents, and, hence, to increase their availability, and to make children more willing to adopt goals that are promoted by parents. In other words, if parents manage to, for instance, promote extrinsic rather than intrinsic goals in a supportive fashion, their children will be more likely to perceive and adopt these goals, which can be expected to lead to higher levels of RWA and SDO. Finally, a certain amount of parental regulation is thought necessary to prevent children from ignoring their parents, and, hence, for children to perceive the goals their parents promote, but too much regulation is thought to decrease adoption of these goals, as extreme levels of parental regulation could come across as overly pressuring (Barber, 1996), and such pressure may provoke rebellion rather than compliance with parental goals (Grusec et al., 2000). In sum, we can expect parental goal promotion to be most effective when parents are need supportive and moderately regulating.

\section{THE PRESENT STUDY}

The goal of the present study is to examine the importance of parenting goals and styles and their interaction in the prediction of adolescent RWA and SDO. For this aim, in a first, cross-sectional study, the importance of parenting goals and styles and goal-style interactions in the prediction of adolescent RWA and SDO was examined. Attention was paid to adolescent representations of parenting goals and styles, because these representations are most likely to yield affect the formation of RWA and SDO. More specifically, parental E/I and conformity goal promotion and the parenting style dimensions that are stressed in developmental research (i.e. need support and regulation) were assessed. In a second, longitudinal study, first, the stability of the findings of Study 1 was examined using a more elaborated measure of parental conformity-related goal 
promotion. Second, we examined whether parenting goals and styles and their interactions predict over-time changes in adolescent RWA and SDO.

\section{STUDY 1}

\section{Method}

\section{Participants}

Participants were 956 12th grade high-school students following an academic track $(N=486)$, a technical $(N=237)$ or an arts $(N=233)$ education who were recruited in the Flemish speaking part of Belgium (Mean age $=17.60$; age range $=16-22 ; 41.27 \%$ male) and took part during regular school hours. Of these participants, 728 came from intact families, 192 had parents who were divorced, 32 had a deceased parent and 1 was an orphan. All participants were born in Belgium, had the Belgian nationality, and had parents of Belgian nationality. All of them belonged to the Flemish majority.

\section{Measures}

Parenting goals. Participants rated a parental goal promotion questionnaire (Vansteenkiste et al., 2006) that assesses to which extent adolescents feel their parents to attach importance to 18 different intrinsic and extrinsic goals in their child rearing by encircling a number between 1 (Not important at all) and 5 (Very Important). The intrinsic goals of self-development (e.g. 'My father finds it important that I develop my talents'), community contribution (e.g. 'My father places high importance on helping other people in need'), and affiliation (e.g. 'My father finds it important that I develop close relationships with a few friends'), and the extrinsic goals of financial success (e.g. 'My father finds it important that I'm financially successful in my life'), social recognition (e.g. 'My father finds it important that I'm admired by several people'), and physical attractiveness (e.g. 'My father finds it important that I'm physically attractive and appealing for others') were assessed (three items each). In addition, three items measured conformity goals (e.g. 'My father finds it important that I respect authority figures').

After control for systematic response sets (see Vansteenkiste et al., 2006), the scree plot of an exploratory factor analysis indicated a two-factor solution (eigenvalues of the first four factors equal 2.82, 1.33, 0.85 and 0.79 for fathers and 2.84, 1.29, 0.88 and 0.80 for mothers), explaining $59 \%$ of the variance for both father and mother ratings. ${ }^{1}$ After Promax rotations, the intrinsic and extrinsic scales loaded on the first factor. Conformity loaded on the second factor. Subsequently, E/I goal promotion scores were computed by subtracting the averaged intrinsic from the averaged extrinsic subscales (Cronbach alpha $=.83$ for fathers and .84 mothers), and conformity goal promotion scores were computed by averaging the conformity items (Cronbach alpha $=.74$ for fathers and .79 for mothers). Positive

\footnotetext{
${ }^{1}$ Parents are assumed to promote different types of goals (e.g. intrinsic goals, extrinsic goals and conformity goals) to a different extent. If parents are perceived to stress different kinds of goals to a similar extent, this can either be substantial (i.e. when parents truly attach equal importance to different type of goals) or it may result from response sets (e.g. yes-saying). By subtracting the overall mean of the goal promotion items from the individual scores, equal goal promotion scores are set to zero. In the resulting factors, deviations from zero can then either be negative (i.e. when people attach more importance to the intrinsic goals than to extrinsic goals) or positive (i.e. when people attach more importance to extrinsic goals than to the intrinsic goals).
} 
E/I scores indicate extrinsic rather than intrinsic goal promotion. Positive conformity scores indicate conformity goal promotion. Our findings are in line with Schwartz (1992) who found the value domain to consist of the orthogonal dimensions Self-Enhancement versus Self-Transcendence, encompassing power values that relate to extrinsic goals, and Conservation versus Openness to Change, encompassing conformity values.

Parenting styles. Participants rated several parenting style dimension items on a five-point Likert scale anchored by Disagree and Agree. Parental need support consisted of responsiveness, autonomy-support and psychological control. Responsiveness was tapped with six items from Schaefer's (1965) Parenting Behavior Inventory (e.g. 'My father makes me feel better after I discussed my worries with him'), autonomy-support was assessed with six autonomy-support items (Grolnick, Ryan, \& Deci, 1991; e.g. 'My father helps me to choose my own direction in life') and psychological control was assessed with six items from Barber's (1996) Psychological Control Scale (e.g. 'My father is always trying to change how I feel or think about things'). Parental regulation was assessed with two scales from Barber's (2002) Parental Regulation Scale, namely 'parental expectations for behavior' (six items, e.g. 'My father has clear expectations for how I should behave in and outside the home') and 'parental enforcement of expectations' (six items, e.g. 'My father punishes me when I do something he doesn't approve of'). The scree plot of an exploratory factor analysis on these five subscales pointed to a two-factor solution (eigenvalues of the first four factors equal 2.43, 1.48, 0.46 and 0.39 for fathers and 2.51, 1.36, 0.48 and 0.41 for mothers), explaining $78 \%$ of the variance for father ratings and $77 \%$ of the variance for mother ratings. After Varimax rotations, responsiveness and autonomy-support loaded positively psychological control loaded negatively on the first factor. The parental regulation scales loaded positively on a second factor. Subsequently, need support scores were computed by averaging the responsiveness, autonomy-support, and (reversed) psychological control items. Regulation scores were computed by averaging the regulation items. Cronbach's alphas were .92 for paternal need support, .92 for maternal need support, .84 for paternal regulation and .85 for maternal regulation.

Authoritarianism. Participants rated a 14-item RWA (Altemeyer, 1981, translated by Meloen, Van der Linden, \& De Witte, 1996; e.g. 'Obedience and respect for authority are among the most important virtues children should learn') and SDO scales (Pratto et al., 1994, translated by Van Hiel \& Duriez, 2002; e.g. 'It's sometimes necessary to step on others to get ahead in life') on a five-point Likert scale anchored by Disagree and Agree. Cronbach's alphas were .71 for RWA and .86 for SDO.

\section{Results}

Preliminary analyses

Because we did not formulate differential hypotheses according to parental gender, mother and father reports of the parenting goals and styles were combined by calculating the mean of the mother and father scores. Combining these scores seemed justified because (a) mean scores of mother and father ratings were virtually identical (the mean difference between both ratings was 0.15 on a five-point scale), (b) the correlations between the ratings were high (with an average correlation of .48) and (c) preliminary analyses showed that mother 
and father ratings yielded almost identical correlation patterns. There were 48 cases in which mother-only scores were used because father data were missing, and 15 cases in which father-only scores were used because mother data were missing.

Table 1 shows response rates, means, standard deviations, range and correlations. From the response rates, it might be clear that, missing data in a particular construct were not estimated but subjected to listwise deletion instead. Due to the large sample size, our analyses attained high power. To preclude small effects from being flagged significant, an alpha-level of .01 was used in all analyses. A small but significant negative correlation was found between E/I and conformity goal promotion. Parental need support and parental regulation were negatively related. Both E/I goal promotion and conformity goal promotion were negatively related to parental need support and positively related to parental regulation. RWA related positively to E/I and conformity goal promotion and parental need support and regulation. SDO was positively related to E/I goal promotion and negatively to need parental support. RWA and SDO related positively. Univariate ANOVAs showed that boys score higher on $\operatorname{SDO}\left[F(1,942)=54.60, p<.001 ; \eta^{2}=.06\right]$ and parental E/I goal promotion $\left[F(1,946)=13.82, p<.001 ; \eta^{2}=.01\right]$, and lower on parental need support $\left[F(1,897)=14.83, p<.001 ; \eta^{2}=.02\right]$. Therefore, gender was inserted as a control variable in all further analyses.

\section{Primary analyses}

Hierarchical regression analyses were performed to determine the effects of the goals and styles on RWA and SDO, and to assess the importance of their interactions. Gender was entered in Step 1. In Step 2a the goals were entered, whereas in Step 2b styles were entered. In Step 3, goals and styles were jointly inserted to examine whether goals and styles predict independent outcome variance after controlling for each other. To examine interactions, goals and styles were centred, interactions were computed and entered in Step 4.

With respect to RWA, after controlling for gender in Step 1, both goals $\left(\Delta R^{2}=.05 ; F(2\right.$, $938)=26.07, p<.001)$ and styles $\left(\Delta R^{2}=.05 ; F(2,938)=23.59, p<.001\right)$ predicted RWA in Steps $2 \mathrm{a}$ and $2 \mathrm{~b}$, respectively. Specifically, RWA was positively predicted by conformity $(\beta=.17, p<.001)$ and $\mathrm{E} / \mathrm{I}$ goal promotion $(\beta=.18, p<.001)$ in Step $2 \mathrm{a}$ and by parental need support $(\beta=.15, p<.01)$ and regulation $(\beta=.19, p<.01)$ in Step $2 b$. These independent effects of goals and styles remained significant in Step 3 when styles and goals were entered simultaneously. Finally, in Step 4, goal-style interactions added to the prediction $\left(\Delta R^{2}=.06 ; F(4,932)=16.93, p<.001\right)$ : Interactions of parental support with both E/I goal promotion and conformity goal promotion were found. To interpret these interactions, the slope of the goals was examined at low (i.e. Mean $-1 S D$ ) and high parental support levels (i.e. Mean $+1 S D$ ). E/I goal promotion predicted RWA at high $(\beta=.31, p<.001)$ but not at low parental support levels $(\beta=.01, n . s$.$) . Conformity goal$ promotion positively predicted RWA at high parental need support levels $(\beta=.34$, $p<.001)$ but negatively predicted RWA at low parental need support levels $(\beta=-.24$, $p<.01)$. The results of Step 4 are reported in the first column in the top half of Table 2.

With respect to SDO, after controlling for gender in Step 1, both goals $\left(\Delta R^{2}=.12 ; F(2\right.$, $937)=64.81, p<.001)$ and styles $\left(\Delta R^{2}=.04 ; F(2,937)=18.43, p<.001\right)$ predicted SDO in Steps $2 \mathrm{a}$ and $2 \mathrm{~b}$, respectively. Specifically, SDO was positively predicted by parental E/I goal promotion $(\beta=.33, p<.001)$, but not by parental conformity goals $(\beta=-.04)$ in Step $2 \mathrm{a}$ and was negatively predicted by parental need support $(\beta=-.19, p<.001)$ but not by parental regulation $(\beta=-.03)$ in Step $2 \mathrm{~b}$. However, when jointly entered in Step 3, SDO was no longer predicted by parental need support. Finally, in Step 4 , the total group of 


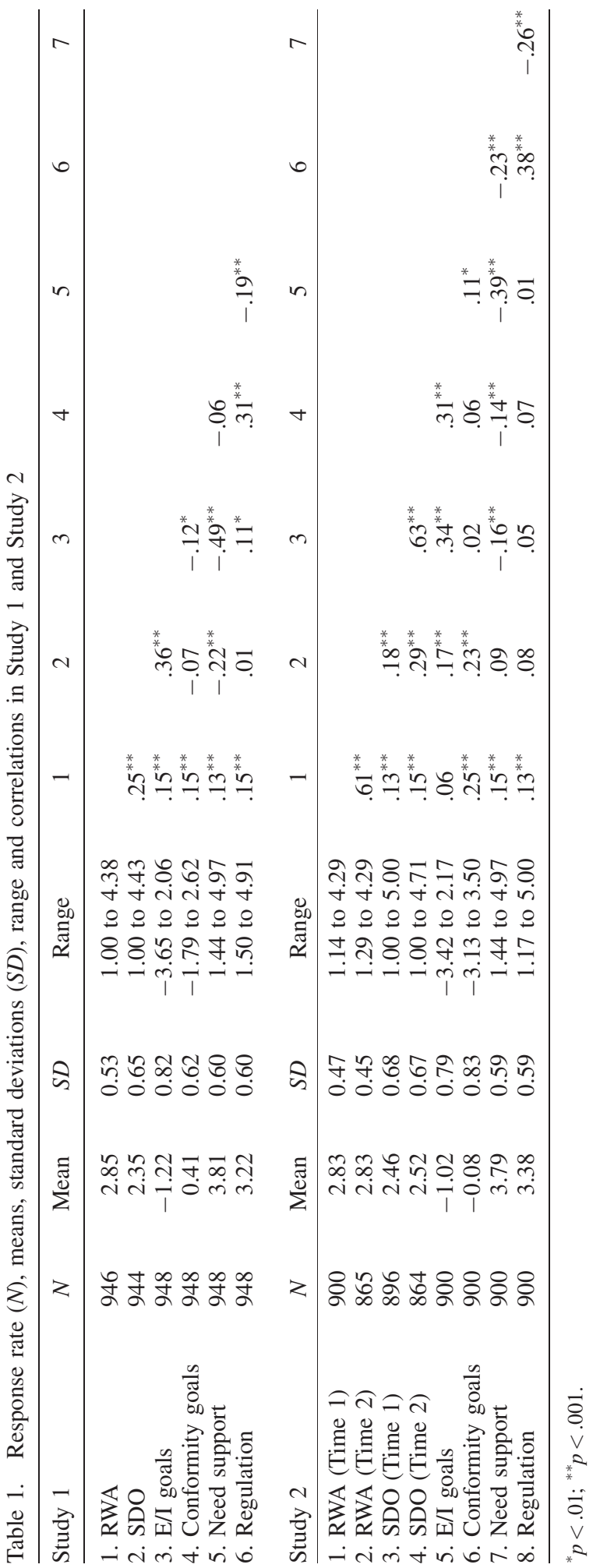


Table 2. Hierarchical regression predicting RWA and SDO in Study 1 and Study 2

\begin{tabular}{lccc}
\hline RWA & Study 1 & Study 2 (Time 1) & Study 2 (Time 2) \\
\hline Gender & .03 & -.08 & .04 \\
RWA (Time 1) & $.30^{* *}$ & $.14^{* *}$ & $.56^{* *}$ \\
E/I goals & $.17^{* *}$ & $.29^{* *}$ & $.12^{* *}$ \\
Conformity goals & $.24^{* *}$ & $.26^{* *}$ & .08 \\
Need support & $.12^{* *}$ & $.11^{*}$ & -.03 \\
Regulation & $.14^{* *}$ & .04 & .03 \\
E/I $\times$ Need support & -.02 & -.06 & .04 \\
E/I $\times$ Regulation & $.18^{* *}$ & $.16^{* *}$ & -.01 \\
Conformity $\times$ Need support & -.06 & -.07 & -.03 \\
Conformity $\times$ Regulation & $.18^{* *}$ & $.19^{* *}$ & $.39^{* *}$ \\
$R^{2}$ & & & \\
& Study & Study $2($ Time & Study $2($ Time 2$)$ \\
SDO & $-.20^{* *}$ & $-.18^{* *}$ & $-.12^{* *}$ \\
\hline Gender & & & $-.56^{* *}$ \\
SDO (Time 1) & $.31^{* *}$ & $.33^{* *}$ & $.11^{* *}$ \\
E/I goals & -.04 & -.02 & -.04 \\
Conformity goals & -.06 & -.04 & .00 \\
Need support & -.02 & .05 & .00 \\
Regulation & .08 & .09 & .02 \\
E/I $\times$ Need support & -.08 & .05 & .02 \\
E/I $\times$ Regulation & -.02 & .05 & -.03 \\
Conformity $\times$ Need support & .02 & .00 & -.05 \\
Conformity $\times$ Regulation & $.19^{* *}$ & $.17^{* *}$ & $.42^{* *}$ \\
$R^{2}$ & & & \\
${ }^{*} p<.01 ;{ }^{* *} p<.001$. & & & \\
& & &
\end{tabular}

goal-style interactions added to the prediction $\left(\Delta R^{2}=.02 ; F(4,931)=5.16, p<.001\right)$ of SDO. However, none of the individual interaction terms reached significance. The results of Step 4 are reported in the first column in the bottom half of Table $2 .^{2}$

\section{Brief discussion}

For RWA, the predicted effects of the parenting goals and styles were supported, and goals and styles independently predicted RWA. More specifically, E/I goal promotion, conformity goal promotion, parental need support and parental regulation all positively predicted adolescent RWA. Inspection of the goal-style interactions indicated that the main effects of the parenting goals should largely be interpreted with caution: E/I goal promotion predicted RWA in need-supportive family climates only, and conformity goal promotion even had an adverse effect on RWA in contexts characterised by low parental support. In

\footnotetext{
${ }^{2}$ Much parenting research has followed a typological approach, which builds on the assumption that it is necessary to consider the interactive effects of different parenting style dimensions. In line with this approach, we computed the interactions between parental need support and parental regulation, between parental need support, parental regulation and E/I goal promotion, and between parental need support, parental regulation and conformity goal promotion. None of these interactions had a significant effect on RWA or SDO. In order not to needlessly complicate our paper, we decided not to report these results. Results of Study 2 confirmed these non-significant findings, both in the cross-sectional and longitudinal analyses.
} 
contrast, parental regulation did not alter the effect of parental goals on RWA. For SDO, results support the predicted positive effect of E/I goal promotion and the predicted negative effect of parental support. However, parental need support ceased to predict SDO after controlling for the shared variance between need support and E/I goal promotion. Neither conformity goal promotion nor parental regulation had any independent effect on adolescent SDO.

\section{STUDY 2}

Study 2 was conducted to cross-validate the findings of Study 1 as well as to look at the longitudinal effects of the parenting goals and styles on adolescent RWA and SDO. This was deemed important because this represents the first systematic assessment of parenting styles and goals in the prediction of RWA and SDO and because we wanted to investigate whether the interaction between goals and styles in the prediction of RWA could be replicated. In addition to replicating findings of Study 1, we aimed to extend them in three significant ways. First, middle instead of late adolescents were sampled, which allowed us to examine the generalisability of the findings across adolescent age groups. Second, the conformity goal promotion measure was elaborated upon. In Study 1, this concept was measured with three items only and was found to load on a different factor than parental E/I goal promotion. However, the items used to assess parental conformity goal promotion were quite closely related to RWA, which might artificially inflate the observed effect of conservation goals on RWA. To avoid the latter, we relied on the Portrait Values Questionnaire (Schwartz et al., 2001), which provides an alternative to the Schwartz (1992) Value Survey and which represents not only a more distal but also a more elaborate conformity measure compared to the one used in Study 1 . In this way, we wanted to capture the broader dimension of the promotion of Conservation versus Openness to Change rather than the narrower concept of conformity goal promotion (see, Schwartz, 1992). Third, we used a longitudinal instead of a cross-sectional design to examine whether styles, goals, and styles by goals would predict changes in SDO and RWA over time.

\section{Method}

\section{Participants}

Data were collected during regular school hours in secondary schools in the Flemish speaking part of Belgium. The first wave of the data collection was conducted in the Fall of 2004 (=Time 1) and consisted of 905 10th grade high-school students following an academic track (Mean age $=14.94$; age range $=14-18 ; 51.22 \%$ male). The second wave was conducted in the Fall of 2005 (=Time 2) and consisted of 867 11th grade high-school students (Mean age $=15.96$; age range $=15-19 ; 50.69 \%$ male). Approximately $80 \%$ of the initial sample participated in the second wave. All participants in the longitudinal sample ( $N=724 ; 49.17 \%$ male) were born in Belgium, had Belgian nationality and had parents of Belgian nationality. All of them belonged to the Flemish majority. Eighty-five per cent lived in an intact family with parents being married and/or living together. Thirteen per cent had divorced parents, and 2\% had at least one deceased parent of which only one was an orphan. Drop-out at Time 2 was mainly due to people having moved to another school, which is not uncommon to do, as the transition to the 11th grade is the time in which 
students have to choose their major, which may imply having to search for a school in which that major is taught. Additionally, a few students may not have passed their 10th grade or might have been ill at the time of the second data collection.

A logistic regression analysis tested if sample attrition (drop-out $=0$; retention $=1$ ) was predicted by gender $($ male $=1$; female $=2$ ), and the study variables at Time 1 . Gender was entered in Step 1, and the parenting goals, styles, RWA and SDO were entered in Step 2. Neither Step 1 nor Step 2 predicted retention (Model $\chi^{2}(1)=6.05$, n.s., for Step 1; Model $\chi^{2}(6)=14.88$, n.s., for Step 2). Hence, no substantial differences emerged between those who participated at Time 2 and those who dropped out, attesting to the a-selectivity of our longitudinal sample in comparison to the initial sample.

\section{Measures}

Parenting goals. To assess parental E/I goal promotion at Time 1, the intrinsic goals of self-development, community contribution and affiliation, and the extrinsic goals of financial success, social recognition and physical attractiveness were assessed (two items each, to be answered on a five-point Likert scale). In addition, participants rated to which degree they feel their father/mother to attach importance to conservation goals. Items were based on the Portrait Values Questionnaire (Schwartz et al., 2001). Items were modified to provide a measure of perceived parental conservation goal promotion rather than personal values. The item 'It is important to him always to behave properly. He wants to avoid doing anything people would say is wrong' was reworded to 'My father finds it important that I behave properly and avoid doing anything people would say is wrong', and the item 'He thinks people should follow rules at all times, even when no-one is watching' was reworded to 'My father finds it important that I follow rules at all times, even when no-one is watching'. Apart from Conformity, the goals of Tradition (two items; i.e. 'My father finds it important that I try to follow the customs of my family and society as a whole'), Self-Direction (two items; i.e. 'My father finds it important that I can make my own decisions, be free, and not dependent on others'), and Stimulation (two items; i.e. 'My father finds it important that I can have an exciting and adventurous life') were also assessed. Previous research has shown that Tradition is highly related to Conformity and that Self-Direction and Stimulation are opposed to these value types (i.e. Schwartz, 1992; Schwartz \& Boehnke, 2003). This way, we aimed to broaden the scope of the parental conformity goal promotion concept that was used in Study 1 to capture a broader parental conservation goal promotion concept that is less obviously related to RWA.

After controlling for systematic response sets (see Study 1), the scree plot of an exploratory factor analysis indicated a two-factor solution (eigenvalues of the first four factors equal 2.74, 2.00, 1.04 and 0.94 for fathers and 2.73, 2.06, 1.10 and 0.97 for mothers), explaining $48 \%$ of the variance for father ratings and $47 \%$ of the variance for mother ratings. For fathers and mothers, after Promax rotations, the intrinsic and extrinsic scales loaded on the first factor, and the conservation goals loaded on the second factor. E/I goal promotion scores were then computed by subtracting the averaged intrinsic from the averaged extrinsic scales (Cronbach alpha $=.74$ for fathers and .75 for mothers), and conservation scores were computed by subtracting the averaged Stimulation and Self-Direction scores from the averaged Conformity and Tradition scores (Cronbach alpha $=.70$ for fathers and .72 for mothers). Positive E/I scores indicate extrinsic rather than intrinsic goal promotion and positive conformity scores indicate the promotion of goals directed towards conservation rather than openness to change. 
Parenting styles. At Time 1, participants completed the same parenting style dimension scales as in Study 1. Again, parental need support was measured with items referring to responsiveness, autonomy-support and psychological control, and parental regulation was measured with items referring to parental expectations for behaviour and parental enforcement of expectations. The scree plot of an exploratory factor analysis on these five subscales pointed to a two-factor solution (eigenvalues of the first four factors equal 2.53, $1.34,0.48$ and 0.33 for fathers and $2.54,1.27,0.55$ and 0.38 for mothers), explaining $78 \%$ and $76 \%$ of the variance for father and mother ratings, respectively. Responsiveness and autonomy-support loaded positively and psychological control loaded negatively on the first factor. The parental regulation scales loaded positively on a second factor. Cronbach's alphas were .91 for paternal and maternal need support, and .85 for paternal and maternal regulation.

Authoritarianism. Both at Time 1 and Time 2, participants rated the same 14-item RWA and SDO scales as in Study 1. Cronbach's alphas were .69 for RWA at Time 1, .85 for SDO at Time 1, .70 for RWA at Time 2, and .86 for SDO at Time 2.

\section{Results}

Preliminary analyses

As in Study 1, mother and father reports of the parenting goals and styles were combined by calculating the mean of the mother and father scores. Combining these scores seemed justified because (a) mean scores of mother and father ratings were virtually identical (the mean difference between both ratings was .09 on a five-point scale), (b) the correlations between the ratings was high (with an average correlation of .49) and (c) correlational analyses showed that the mother and father ratings yielded similar correlational patterns. There were 32 cases in which mother-only scores were used because father data were missing, and 8 cases in which father-only scores were used.

Table 1 shows response rates, means, standard deviations, range and correlations. E/I and conservation goal promotion related slightly but significantly positively. Parental need support and parental regulation were negatively correlated. E/I goal promotion related negatively to parental need support but was unrelated to parental regulation, and conservation goal promotion related negatively to parental support and positively to parental regulation. RWA at Time 1 related positively to conservation goal promotion and parental need support and regulation. RWA at Time 2 related positively to both E/I and conservation goal promotion, but not to parental need support and regulation. SDO at Time 1 and Time 2 was positively related to E/I goal promotion and negatively to parental support. At each point in time, RWA and SDO related slightly positively, and across time, their correlation was also slightly positive. Univariate ANOVAs showed that boys score higher than girls on both SDO at Time $1\left[F(1,894)=42.41, p<.001 ; \eta^{2}=.05\right]$ and SDO at Time $2\left[F(1,720)=57.10, p<.001 ; \eta^{2}=.07\right]$. No other gender differences were observed. Because of the gender differences in SDO at both Time 1 and Time 2, like in Study 1, gender was inserted as a control variable in all further analyses.

\section{Primary analyses}

Cross-sectional analyses. To consolidate the findings of Study 1, we performed a series of hierarchical regression analyses to determine the effects of the parenting goals and styles and possible interactions on RWA and SDO at Time 1 (i.e. at the cross-sectional level). As 
in Study 1, gender was entered as a control variable in Step 1. In Steps 2a and 2b, parenting goals and styles were entered, respectively. In Step 3, the parenting styles and goals were jointly inserted. Finally, to examine whether there were significant goal-style interactions, these variables were centred, and interactions were computed and entered in Step 4. After controlling for gender, both goals $\left(\Delta R^{2}=.06 ; F(2,894)=30.98, p<.001\right)$ and styles $\left(\Delta R^{2}=.06 ; F(2,894)=27.25, p<.001\right)$ predicted RWA in Steps $2 \mathrm{a}$ and $2 \mathrm{~b}$, respectively. Specifically, RWA was positively predicted by E/I goal promotion $(\beta=.14, p<.001)$ and conservation goals $(\beta=.25, p<.001)$ in Step 2 a and was positively predicted by parental need support $(\beta=.21, p<.001)$ and parental regulation $(\beta=.19, p<.001)$ in Step $2 \mathrm{~b}$. When goals and styles were jointly entered in Step 3, the effects found in Steps $2 \mathrm{a}$ and $2 \mathrm{~b}$ remained unchanged, indicating that both types of goals as well parental regulation and parental need support yielded an independent effect on RWA. Finally, in Step 4, the goal-style interactions added to the prediction $\left(\Delta R^{2}=.05 ; F(4,888)=14.32, p<.001\right)$ : A significant interaction of parental need support with conservation goal promotion was found. To interpret this interaction, the slope of the conservation goals was examined at low (i.e. Mean $-1 S D$ ) and high parental support levels (i.e. Mean $+1 S D$ ). As in Study 1, conservation goal promotion positively predicted RWA at high parental need support levels $(\beta=.45, p<.001)$ but did not significantly predict RWA at low parental need support levels $(\beta=-.10$, n.s. $)$.

As for the prediction of SDO, goals $\left(\Delta R^{2}=.11 ; F(2,890)=56.08, p<.001\right)$ and styles $\left(\Delta R^{2}=.02 ; F(2,890)=11.25, p<.001\right)$ predicted SDO in Steps $2 \mathrm{a}$ and $2 \mathrm{~b}$, respectively. Specifically, E/I goal promotion $(\beta=.33, p<.001)$ positively predicted SDO, whereas conservation goals $(\beta=-.01)$ were unrelated to SDO in Step 2a. In Step 2b, need support was negatively related $(\beta=-.15, p<.001)$ to $\mathrm{SDO}$, whereas regulation $(\beta=-.02)$ was unrelated. However, when parental styles and goals were jointly entered in Step 3, SDO was predicted by E/I goal promotion only. As in Study 1, goal-style interactions did not add to the prediction of SDO in Step $4\left(\Delta R^{2}=.01 ; F(4,884)=2.71, n . s\right.$. $)$. The results of Step 4 are reported in the second column of Table 2 (top half for RWA, bottom half for SDO).

Longitudinal analyses. A second set of hierarchical regression analyses was performed in order to determine the effects of the parenting goals and styles and goal-style interactions on changes in RWA and SDO over time. For this purpose, in Step 1, not only gender, but also either RWA at Time 1 (for the prediction of RWA at Time 2) or SDO at Time 1 (for the prediction of SDO at Time 2) were entered. This allowed us to control for the stability over time in these constructs, and, hence, to focus on actual changes. Then, we proceeded in the same way as for the cross-sectional analyses. In Steps $2 a$ and $2 b$, the parenting goals or styles were entered, respectively. In Step 3, the parenting styles and goals were jointly inserted. Finally, the interaction terms were computed and entered in Step 4. Concerning RWA, the parenting goals $\left(\Delta R^{2}=.01 ; F(2,714)=7.63, p<.001\right)$ predicted over-time changes in RWA (Step 2a), whereas the parenting styles $\left(\Delta R^{2}=.00\right.$; $F(2,714)=0.33$, n.s. $)$ did not (Step $2 \mathrm{~b})$. As for the parenting goals, both conservation goals $(\beta=.10, p<.01)$ and $\mathrm{E} / \mathrm{I}$ goal promotion $(\beta=.12, p<.001)$ predicted over-time changes in RWA. These effects remained unchanged after adding parenting styles in Step 3. Finally, contrary to the cross-sectional analyses, goal-style interactions did not add to the prediction $\left(\Delta R^{2}=.00 ; F(4,708)=0.60\right.$, n.s. $)$ in Step 4 .

Concerning SDO, whereas the parenting goals $\left(\Delta R^{2}=.01 ; F(2,710)=7.30, p<.001\right)$ predicted over-time changes in SDO (Step 2a), the parenting styles $\left(\Delta R^{2}=.00 ; F(2\right.$, 
$710)=0.86$, n.s. $)$ did not (Step 2b). Specifically, SDO at Time 2 was predicted by E/I goal promotion $(\beta=.11, p<.001)$, but not by conservation goals $(\beta=.02)$. This effect remained significant after entering parenting styles in Step 3. Finally, as in the cross-sectional analyses, goal-style interactions did not add to the prediction in Step 4 $\left(\Delta R^{2}=.00 ; F(4,704)=0.82, n . s.\right)$. Results of Step 4 are reported in the third column of Table 2 (top half for RWA, bottom half for SDO).

\section{Brief discussion}

In line with Study 1, the predicted effects of the parenting goals and styles on RWA were found in the cross-sectional analyses. The parenting goals and styles independently predicted RWA at Time 1. More specifically, E/I goal promotion, conservation goal promotion, parental need support and parental regulation all positively predicted adolescent RWA. In line with Study 1, inspection of the goal-style interactions indicated that the main effect of parental conservation goal promotion is qualified by the effect of parenting style. Conservation goal promotion predicted RWA in need-supportive family climates only. In contrast to Study 1, no interaction effect was found between E/I goal promotion and parental need support, suggesting that E/I goal promotion positively predicts RWA regardless of the extent to which parents are experienced as supportive or not. The longitudinal analyses showed that, in contrast to parental goals, parental style dimensions did not predict over-time changes in RWA. More specifically, E/I goal promotion and conservation goal promotion were the only significant predictors of RWA at Time 2 over and above gender and RWA at Time 1. Different from the cross-sectional analyses, goal-style interactions did not contribute to the prediction of RWA at Time 2 either.

In line with Study 1, when all the parenting variables were analysed simultaneously, E/I goal promotion was the only variable that predicted SDO in the cross-sectional analyses. More specifically, E/I goal promotion positively predicted adolescent SDO at Time 1. Goal-style interactions did not add to the prediction of SDO at Time 1. Additionally, longitudinal analyses showed that parental E/I goal promotion also predicts over-time changes in SDO. More specifically, E/I goal promotion predicted SDO at Time 2 over and above gender and SDO at Time 1. Parental styles and goal-style interactions did not contribute to the prediction of SDO at Time 2.

\section{GENERAL DISCUSSION}

Although various researchers have theorised about the impact of parenting on the development of RWA and SDO, this question has received little systematic empirical attention. The goal of the present study was to examine the importance of two different aspects of parenting, that is, the type of goals parents promote during their child rearing and the style they use when relating to their children. Moreover, we examined whether the effect of parenting goals on RWA and SDO would differ depending on the affective quality of the family climate. As far as RWA is concerned, results show that, although parental goals and styles are equally good predictors that also interact with each other in the prediction of RWA at a specific point in time, parental goals are the only parenting variables that predict over-time changes in RWA. As far as SDO is concerned, results show that, when the effect of parenting goals and styles on SDO are simultaneously investigated, the 
parental promotion of extrinsic rather than intrinsic goals is the only parenting variable predicting SDO at a given point in time. Moreover, parental promotion of extrinsic rather than intrinsic goals also predicted an increase in SDO over time. These results are discussed in greater detail in the following paragraph.

For RWA, the type of goals emphasised by parents in their child rearing as well as the parenting style yielded an independent effect on RWA at the concurrent level. Thus, we were able to detect four independent parenting sources that predict adolescents' authoritarian attitudes. Specifically, if parents highlight the importance of conservation and E/I goals, their adolescents are more likely to adopt an authoritarian attitude. Furthermore, if parents clearly communicate their expectations and punish the transgression of expectations, adolescents are likely to adopt a critical attitude towards norm violators in our society. Interestingly, parental need support was also predictive of RWA. Finally, if parents create a responsive and autonomy-supportive climate, adolescents are more likely to endorse a submissive attitude towards authority figures. This is an intriguing and perhaps somewhat contra-intuitive finding, which deserves some more explanation. Two different elements might explain the within-time correlation between RWA and perceived need-supportive parenting. First, this correlation might be understood in terms of the nature of RWA itself. When authoritarian individuals adopt a submissive attitude and display strong respect for authority figures, they are also likely to idealise and glorify their parents. Thus, adolescents high on RWA might perceive their parents as more supportive while this does not correspond to reality. Second, the positive correlation between need-supportive parenting and RWA might not only reflect adolescent response bias, but might represent a true effect. That is, parents of authoritarian adolescents might actually be more need supportive. Parents may increase their support as a positive response to their child conforming to their wishes and expectations. Future research might want to further examine these two possibilities by including a social responsibility scale to rule out the first explanation and by assessing need-supportive parenting and RWA on two measurement moments to examine whether authoritarian adolescents provoke more need-supportive parenting.

In addition to the observed main effects, parental need support interacted with conservation (Study 1 and Study 2) as well as with E/I goal promotion (Study 1) in the prediction of RWA. Inspection of the interactions suggested that goal promotion leads to RWA at high levels of parental need support only. These findings testify to the importance of a supportive family climate for parental goal promotion to be effective (e.g. Grusec et al., 2000; Knafo \& Schwartz, 2003). However, it must be noted that this interaction effect was quite specific, as parental need support but not parental regulation served as a moderator, and rather unstable, as these interactions were not replicated in the longitudinal analyses of Study 2. In fact, parenting goals appeared to be the only predictors of changes in RWA over time. Parents who emphasise the importance of sticking to existing societal expectations rather than being open to change and pursuing extrinsic goals such as amassing material wealth and garnering social status instead of intrinsic goals seem to promote increases in RWA over time among their adolescents. The longitudinal analyses suggest that parental styles neither influence changes in RWA over time nor moderate the influence of parenting goal promotion on changes over time in RWA. As a result, the cross-sectional main effects of parenting styles and the interaction between styles and goals should be interpreted with caution in light of these null-findings at the longitudinal level.

For SDO, as suggested by Duckitt (2001), it was found that parental need support, when entered separately, negatively predicted SDO. Apparently, a warm and autonomy- 
supportive family climate that allows adolescents to pursue their personal interests and values prevents adolescents from becoming harsh, ruthless and unfeeling to others (characteristics that apply to social dominators). However, this main effect no longer reached significance after inserting parental goal promotion in the regression equation. Thus, the initial observed effect of need-supportive parenting on SDO is likely to be due to the fact that parents who promote intrinsic rather than extrinsic goals are more likely to do this in a need-supportive fashion. In fact, E/I goal promotion was the most important predictor of SDO, as it was the only variable that predicted SDO concurrently and longitudinally. Apparently, parents who strongly emphasise the pursuit of extrinsic goals, such as acquiring material success, fame and physical appeal, promote a more aggressive attitude towards other groups among their adolescents. The increased adoption of such a socially dominant attitude is likely to be perceived as instrumental by adolescents to attain the extrinsic goals that are held for them by their parents.

It should be stressed that, even though our data show parental style dimensions to have no effect on over-time changes in RWA and SDO, this does not mean that there are no such effects. First, it might be that a 1-year interval is too short for differences in parenting style dimensions to result in significant attitude changes. Second, it might be that parenting style dimensions do not have a direct impact on RWA and SDO but have an indirect effect through their influences on related personality features (e.g. openness to experience, tough-mindedness and empathy) that might in turn influence RWA and SDO (cf. Duckitt, 2001; Soenens, Duriez, Vansteenkiste, \& Goossens, in press). Hence, future research might try to follow adolescents for a longer period of time and might include possibly mediating personality features as well. Third, as suggested by Adorno et al. (1950), parental style dimensions might be especially important in early childhood. Our data do not directly address this possibility, as we sampled adolescents only. However, our data do suggest, that research needs to move beyond only tapping the extent to which children experience harsh punishment and little parental warmth during early childhood, and might do well in examining the type of goals parents promote. More specifically, our findings suggest that parental goal promotion efforts have a substantial impact on the development of RWA and SDO during adolescence.

As for the effects of parental goal promotion on adolescent attitudes, an important question to be raised is why some parents are more likely than others to promote certain goals. Previous research has stressed the parental importance towards the development of RWA (Altemeyer, 1988; Vollebergh \& Raaijmakers, 1991) and other socio-political attitudes (Vollebergh, Iedema, \& Raaijmakers, 1999) by showing that adolescent attitudes often resemble the ones of their parents. Therefore, parents' own attitudes may be an important predictor of their goal promotion. In fact, if parents high on RWA or SDO are likely to promote goals that foster RWA and SDO in their children, the next question would be whether parents pass their attitudes onto their children through the promotion of certain goals. In other words, future research might examine whether parental goal promotion plays a mediating role in the transmission of authoritarian attitudes from parents to their children.

\section{Limitations and future directions}

The present research has several limitations. First, all measures are adolescent self-reports. This increases the likelihood of shared method variance. Although adolescent self-reports may be the most valid means to assess parental treatment (Barber, 1996), we encourage researchers to use other indices as well, as adolescent perceptions of parenting construct 
might be distorted and inaccurate. These might include parental self-reports, observer ratings or peer-nominations to explore whether parental goals or styles predict affiliation with socially dominant and authoritarian friends. However, it should be stressed that research using parent and adolescent reports as indicators of parental E/I goal promotion yielded similar results (Vansteenkiste, Duriez et al., 2006), indicating that the associations obtained between parental goal promotion and RWA and SDO are not due to shared method variance.

Second, given that transactional socialisation theories (e.g. Caspi, 1998) stress that children also influence their parents, the possibility also exists that adolescent attitudes provoke parents to adjust the goals they promote, which, in turn, might even lead to an adjustment of parental attitudes. For instance, if parents perceive their child to hold authoritarian submissive beliefs, this might lead parents to increase their reliance on extrinsic goal promotion and/or conservation goal promotion in an attempt to motivate their child. This might, in turn, increase the perception of the parents as people who promote extrinsic and/or conservation goals. Future research might further examine this possibility.

Third, future research might also want to explore whether parental goals and/or styles impact on other variables. Based on previous research on personal goal pursuits (e.g. Kasser \& Ryan, 1996), we predict parental E/I goal promotion to relate negatively to well-being. For parental conservation goal promotion, no obvious short-term effect is expected, because it will lead the child to adopt a normative identity style, which, in turn leads the child to shut itself off from belief-threatening information and experiences (Soenens, Duriez, \& Goossens, 2005). However, this way of dealing with new information might result in decreased well-being in the long run. As far as parenting styles are concerned, research has shown that parental support and appropriate regulation yield beneficial well-being outcomes (e.g. Gray \& Steinberg, 1999). However, although socialisation models (e.g. Darling \& Steinberg, 1993) assume that parenting goals and styles interact to predict child adjustment, little research has actually examined their combined influence on indicators of adolescents' well-being.

Fourth, the present study limited itself to parental influence. Future research might want to compare the size of this influence to the size of the influence of other socialisation agents (e.g. peers, media, school). Furthermore, it could be examined whether the observed impact of E/I goal promotion on SDO and RWA could be buffered by socialising agents that value the pursuit of intrinsic rather than extrinsic goals. Thus, in addition to examining the independent effect of different socialisation figures, their interactive effects could also be studied as to examine whether some socialisation figures play a buffering role to protect adolescents against the negative impact of others.

\section{Conclusion}

The present research sheds light on one important social-contextual factor that helps to understand why some adolescents' develop authoritarian and socially dominant ideas: The parents. If parents promote the attainment of extrinsic goals such as financial success, social status and physical attractiveness at the expense of intrinsic goals such as self-development, community contribution and affiliation, their offspring is more likely to adopt prejudice. This occurs because the parental promotion of extrinsic goals at the expense of intrinsic goals leads adolescents to adopt socially dominant attitudes and, to a lesser extent, to rigidly focus on the adherence to societal norms. In a similar vein, if 
parents promote conservation goals, their adolescent children are likely to rigidly focus on the adherence to societal norms, to be critical of norm transgressors, and to shut themselves off from information and experiences that are incompatible with their hardcore beliefs. Hence, in order to rid society of discriminatory stances, parents might highlight the importance of satisfying relations, being willing to help others without expecting something in return, developing one's talents, and relying on their own judgments. But this is not the only reason why parents should try to refrain from the promotion of extrinsic rather than intrinsic goals. As previous research suggests, relying on intrinsic rather than extrinsic goals is also likely to increase the general well-being of their children (Kasser, 2002) as well as their academic functioning (Vansteenkiste, Lens et al., 2006).

\section{REFERENCES}

Adorno, T. W., Frenkel-Brunswik, E., Levinson, D., \& Sanford, R. N. (1950). The authoritarian personality. New York: Harper.

Altemeyer, B. (1981). Right-wing authoritarianism. Manitoba: University of Manitoba Press.

Altemeyer, B. (1988). Enemies of freedom. London: Jossey Bass.

Altemeyer, B. (1998). The other "authoritarian personality". In M. P. Zanna (Ed.), Advances in experimental social psychology (pp. 47-92). San Diego: Academic Press.

Asendorpf, J. B., \& van Aken, M. A. G. (2003). Personality-relationship transaction in adolescence: Core versus surface personality characteristics. Journal of Personality, 71, 629-666.

Barber, B. K. (1996). Parental psychological control: Revisiting a neglected construct. Child Development, 67, 3296-3319.

Barber, B. K. (1997). Introduction: Adolescent socialization in context-The role of connection, regulation and autonomy in the family. Journal of Adolescent Research, 12, 5-11.

Barber, B. K. (2002). Regulation as a Multicultural Concept and Construct for Adolescent Health and Development. Paper presented at the World Health Organization Meeting. Geneva, April 16-20, 2002.

Baumeister, R., \& Leary, M. R. (1995). The need to belong: Desire for interpersonal attachments as a fundamental human motivation. Psychological Bulletin, 117, 497-529.

Caspi, A. (1998). Personality development across the life course. In W. Damon (Ed.), Handbook of child psychology: Social, emotional, and personality development (Vol. 3, pp. 311-388). New York: Wiley.

Darling, N., \& Steinberg, L. (1993). Parenting style as context: An integrative model. Psychological Bulletin, 113, 487-496.

Deci, E. L. (1975). Intrinsic motivation. New York: Plenum.

Deci, E. L., \& Ryan, R. M. (2000). The "what" and the "why" of goal pursuits: Human needs and the self-determination of behavior. Psychological Inquiry, 11, 227-268.

Duckitt, J. (2001). A dual-process cognitive-motivational theory of ideology and prejudice. In M. P. Zanna (Ed.), Advances in experimental social psychology (Vol. 33, pp. 41-113). San Diego, CA: Academic Press.

Duckitt, J., Wagner, C., du Plessis, I., \& Birum, I. (2002). The psychological basis of ideology and prejudice: Testing a dual process model. Journal of Personality and Social Psychology, 83, 75-93.

Duriez, B., \& Van Hiel, A. (2002). The march of modern fascism: A comparison of social dominance orientation and authoritarianism. Personality and Individual Differences, 32, 1199-1213.

Duriez, B., Van Hiel, A., \& Kossowska, M. (2005). Authoritarianism and social dominance in Western and Eastern Europe: The importance of the socio-political context and of political interest and involvement. Political Psychology, 26, 299-320.

Duriez, B., Vansteenkiste, M., Soenens, B., \& De Witte, H. (in press). The social costs of extrinsic relative to intrinsic goal pursuits: Their relation with social dominance and racial and ethnic prejudice. Journal of Personality.

Gray, M. R., \& Steinberg, L. (1999). Unpacking authoritative parenting: Reassessing a multidimensional construct. Journal of Marriage and Family, 61, 574-587. 
Grolnick, W. S. (2003). The psychology of parental control: How well-meant parenting backfires. Mahwah, NJ: Erlbaum.

Grolnick, W. S., Ryan, R. M., \& Deci, E. (1991). Inner resources for school achievement: Motivational mediators of children's perceptions of their parents. Journal of Educational Psychology, 83, 508-517.

Grouzet, F. M. E., Kasser, T., Ahuvia, A., Fernandez-Dols, J. M., Kim, Y., Lau, S., Ryan, R. M., Saunders, S., Schmuck, P., \& Sheldon, K. (2006). The structure of goal contents across 15 cultures. Journal of Personality and Social Psychology, 89, 800-816.

Grusec, J. E., Goodnow, J. J., \& Kuczynski, L. (2000). New directions in analyses of parenting contributions to children's acquisition of values. Child Development, 71, 205-211.

Kasser, T. (2002). The high price of materialism. London: MIT.

Kasser, T., \& Ryan, R. M. (1996). Further examining the American dream: Differential correlates of intrinsic and extrinsic goals. Personality and Social Psychology Bulletin, 22, 280-287.

Kasser, T., Ryan, R. M., Zax, M., \& Sameroff, A. J. (1995). The relations of maternal and social environments to late adolescent's materialistic and pro-social values. Developmental Psychology, 31, 907-914.

Knafo, A., \& Schwartz, S. H. (2003). Parenting and adolescents' accuracy in perceiving parental values. Child Development, 74, 595-611.

Maccoby, E. E., \& Martin, J. A. (1983). Socialization in the context of the family: Parent-child interaction. In P. H. Mussen (Series Ed.), \& E. M. Hetherington (Vol. Ed.), Handbook of child psychology: Socialization, personality and social development (Vol. 4, 4th ed., pp. 1-110). New York: Wiley.

Meloen, J., Van der Linden, G., \& De Witte, H. (1996). A test of the approaches of Adorno et al., Lederer and Altemeyer of authoritarianism in Belgian Flanders: A research note. Political Psychology, 17, 643-656.

Milburn, M. A., Conrad, S. D., Sala, F., \& Carberry, S. (1995). Childhood punishment, denial, and political attitudes. Political Psychology, 16, 447-478.

Niemiec, C., Lynch, M., Vansteenkiste, M., Bernstein, J., Deci, E. L., \& Ryan, R. M. (2006). The antecedents and consequences of adolescents' autonomous motivation for academics: A selfdetermination theory perspective on socialization. Journal of Adolescence, 26, 761-775.

Pratto, F., Sidanius, J., Stallworth, L. M., \& Malle, B. F. (1994). Social dominance orientation: A personality variable predicting social and political attitudes. Journal of Personality and Social Psychology, 67, 741-763.

Schaefer, E. S. (1965). Children's reports of parental behavior: An inventory. Child Development, 36, 413-424.

Schwartz, S. H. (1992). Universals in the content and structure of values: Theoretical advances and empirical tests in 20 countries. In M. P. Zanna (Ed.), Advances in experimental social psychology (Vol. 25, pp. 1-65). San Diego/London: Academic Press.

Schwartz, S. H., \& Boehnke, K. (2003). Evaluating the structure of human values with confirmatory factor analysis. Journal of Research in Personality, 38, 230-255.

Schwartz, S. H., Melech, G., Lehmann, A., Burgess, S., Harris, M., \& Owens, V. (2001). Extending the cross-cultural validity of the theory of basic human values with a different method of measurement. Journal of Cross-Cultural Psychology, 32, 519-542.

Sears, D. O. (1990). Wither political socialization research. In O. Ichilov (Ed.), Political socialization, citizenship education, and democracy (pp. 69-97). New York: Teachers College Press.

Soenens, B., Duriez, B., \& Goossens, L. (2005). Social-psychological profiles of identity styles: Attitudinal and social-cognitive correlates in late adolescence. Journal of Adolescence, 28, $107-125$.

Soenens, B., Duriez, B., Vansteenkiste, M., \& Goossens, L. (in press). The intergenerational transmission of empathy-related responding in adolescence: The role of maternal support. Personality and Social Psychology Bulletin.

Tajfel, H., \& Turner, J. (1979). A integrative theory of intergroup conflict. In W. Austin, \& S. Worchel (Eds.), The social psychology of intergroup relations (pp. 33-47). Monterey, CA: Brooks/Cole.

Van Hiel, A., \& Duriez, B. (2002). Een meetinstrument voor individuele verschillen in Sociale Dominantie Oriëntatie. Nederlands Tijdschrift voor de Psychologie en haar Grensgebieden, 57, $114-116$. 
Van Hiel, A., Pandelaere, M., \& Duriez, B. (2004). The impact of need for closure on conservative beliefs and racial prejudice: Differential mediation by authoritarian submission and authoritarian dominance. Personality and Social Psychology Bulletin, 30, 824-837.

Vansteenkiste, M., Duriez, B., Soenens, B., \& De Witte, H. (2006). Understanding the effects of parental extrinsic versus intrinsic goal promotion and parental educational level on adolescent ethnic prejudice. (manuscript submitted for publication).

Vansteenkiste, M., Lens, W., \& Deci, E. L. (2006). Intrinsic versus extrinsic goal-contents in self-determination theory: Another look at the quality of academic motivation. Educational Psychologist, 41, 19-31.

Vansteenkiste, M., Simons, J., Lens, W., Sheldon, K. M., \& Deci, E. L. (2004). Motivating learning, performance, and persistence: The synergistic role of intrinsic goals and autonomy-support. Journal of Personality and Social Psychology, 87, 246-260.

Vansteenkiste, M., Simons, J., Lens, W., Soenens, B., Matos, L., \& Lacante, M. (2004). "Less is sometimes more": Goal-content matters. Journal of Educational Psychology, 96, 755-764.

Vollebergh, W., Iedema, J., \& Raaijmakers, Q. (1999). The intergenerational transmission of cultural and economic conservatism. In H. De Witte, \& P. Scheepers (Eds.), Ideology in the low countries: Trends, models and lacunae. Assen: Van Gorcum.

Vollebergh, W. A. M., Iedema, J., \& Raaijmakers, Q. A. W. (2001). Intergenerational transmission and the formation of cultural orientations in adolescence and young adulthood. Journal of Marriage and the Family, 63, 1185-1198.

Vollebergh, W., \& Raaijmakers, Q. (1991). De intergenerationele overdracht van autoritarisme. In P. Scheepers, \& R. Eisinga (Eds.), Onderdanig en intolerant: Lacunes en controverses in autoritarisme-studies (pp. 61-79). Nijmegen: Instituut voor Toegepaste Sociale Wetenschappen. 